\title{
Combinatorial auction design
}

\begin{abstract}
David Portera,b, Stephen Rassentia, Anil Roopnarinec, and Vernon Smith ${ }^{a}$
aInterdisciplinary Center for Economic Science, George Mason University, Fairfax, VA 22030; and 'Cybernomics Inc., 2212 E. Camino El Ganado, Tucson, AZ 85718
\end{abstract}

Contributed by Vernon Smith, June 17, 2003

Combinatorial auctions allow for more expressive bidding in which participants can submit package bids with logical constraints that limit allowable outcomes. This type of auction can be useful when participants' values are complementary or when participants have production and financial constraints. However, combinatorial auctions are currently rare in practice. The main problems confronted in implementing these auctions are that they have computational uncertainty (i.e., there is no guarantee that the winning bids for such an auction can be found in a "reasonable" amount of time when the number of bidders and items becomes larger) and that the auction is cognitively complex and can lead participants to pursue perverse bidding strategies. This article describes a type of combinatorial auction that, during laboratory testing, eliminated these problems and produced extremely efficient outcomes.

$\mathrm{c}$ ombinatorial auctions enhance our ability to allocate multiple resources efficiently in complex economic environments. They explicitly allow buyers and sellers of goods and services to bid on packages of items with related values or costs (for example, "I bid \$10 to buy one unit of item A and two units of item B, but I won't pay anything unless I get everything"). They also allow buyers, sellers, and the auctioneer to impose logical constraints that limit the feasible set of auction allocations (for example, "I bid $\$ 12$ to buy two units of item C or $\$ 15$ to buy three units of item D, but I don't want both"). Finally, they can handle functional relationships among bids or allocations such as budget constraints or aggregation limits that allow many bids to be connected together (for example, "I won't spend more than a total of $\$ 35$ on all my bids" or "this auction will allocate no more than a total of seven units of items F, G, and H").

There are several reasons to prefer to have the bidding message space expanded beyond the simple message space used in traditional single-commodity auctions. As Bykowsky et al. (1) point out, when values have strong complementarities, there is a danger of "financial exposure" that results in losses to bidders if combinatorial bidding is not allowed. For example, in the case of complementary items such as airport take-off and landing times, the ability to reduce uncertainty to the bidder by allowing him to precisely declare his object of value, a cycle of slots for an entire daily flight pattern, is obvious: Failing to acquire one component slot ruins the value of the flight cycle. ${ }^{d}$ In the same situation, substitution possibilities would also be important to consider: If flight cycle A is not won, cycle B may be an appropriate but less-valuable substitute for the crew and equipment available. Allocation inefficiencies due to financial exposure in noncombinatorial auctions have been demonstrated frequently in experiments beginning with ref. 2 (see also refs. 3-6).

This article is concerned with designing a transparent, efficient, and practical combinatorial buyers' auction for multiple distinct items with perhaps multiple units of each available. We focused this endeavor around the past auctions, debate, proposals, and tests precipitated by the quest of the Federal Communications Commission (FCC) for the design of the "perfect" spectrum auction. Many of the design principles ultimately implemented by us are easily extensible to more complex twosided $^{\mathrm{e}}$ negotiations with environmental ${ }^{\mathrm{f}}$ constraints. We begin by mimicking the original FCC debate, describing several combinatorial auction designs and their potential problems. We next present some pertinent laboratory results of auction design already tried. We then describe a combinatorial auction design that we invented to eliminate many of the problems found in previous designs. We finish with the description and testing of three auctions previously untested in the laboratory, the one currently used by the FCC in the field, a combinatorial auction design solicited by the FCC but not yet implemented, and our own design.

\section{FCC Auction-Design Process}

The FCC conducted several high-priced auctions for communications' spectra during the 1990s. The simultaneous multiround auction (SMR) design used by the FCC has several notable features:

- Simultaneous auction of the various licenses offered.

- Iterative procedure allowing round-by-round update of bids.

- Activity rules demanding continuous participation at minimum bid increments.

After much discussion and debate but no controlled testing, the FCC chose to implement the SMR. The FCC did not originally opt for a combinatorial form of auction for three stated reasons:

1. Computational uncertainty: At any point during a combinatorial auction, the selection of the winning bids and what it would cost for competition to displace them typically requires the solution of integer-programming problems. These problems are notorious for being computationally burdensome: technically described as nondeterministic polynomial time complete or hard problems. At issue here is that there is no guarantee that the solution for such a problem can be found in a "reasonable" amount of time when the number of bidders and items becomes larger.

2. Bidding complexity: Combinatorial auctions would be burdensome and difficult for participants and the auctioneer for at least two reasons. First, there are inconceivably many packages on which a bidder might want to place bids, and selecting any subset may be strategically awkward and provide the auctioneer with incomplete information. ${ }^{\mathrm{g}}$ Second, there is

Abbreviations: FCC, Federal Communications Commission; SMR, simultaneous multiround auction; IP, integer program; CRA, Charles River and Associates; CC, combinatorial clock. See commentary on page 10590.

bTo whom correspondence should be addressed. E-mail: dporter4@gmu.edu.

dIn some instances, such risk may reduce the aggressiveness with which bidders bid and, in so doing, may lead to a misassignment of items. In other instances, bidders may bid too aggressively and, in so doing, obtain items at prices that exceed the value the bidder places on those items.

eA buyers' auction becomes two-sided when sellers may participate as buyers of their own offerings.

fFor example, conservation of flow in network distribution systems or storage- and channelcapacity limits can be applied as allocation constraints in the auction proposed.

9This is the supermarket problem also referred to at various FCC discussions as the $2^{\mathrm{N}}$ boogie man because there are that many combinations of items that a bidder must consider. Suppose you have $\$ 100$ in your pocket and you are standing at the entrance to the supermarket. You despondently realize that you may never come out because you must first consider every possible way you might fill your shopping cart.

() 2003 by The National Academy of Sciences of the USA 
a computational problem for the bidder to determine how much to bid to be successful.

3. Threshold problem: Combinatorial auctions present the following strategic impediment to efficient outcomes. Suppose each of two small bidders is bidding on a separate item, but a third bidder is bidding on a package that contains both items. Then the two small bidders must implicitly coordinate through their bidding to ascertain what price each will pay in order for the sum of both bids to exceed the package bid.

The FCC chose to implement the SMR design in all of its spectrum auctions rather than confront the issues discussed above. Bidders in an SMR auction who had superadditive values for a particular package of licenses were subject to financial exposure if they miss acquiring at least one of those licenses. The FCC auctions implemented a withdrawal rule to "reduce" the potential financial exposure of the bidders; that is, bidders had the right to withdraw bids on particular licenses subject to the fact that they were obligated to pay the difference between their own and the final winning bid if it was less. This and other SMR rules led to results in various FCC auctions that revealed some interesting perverse strategies. In particular, individuals would withdraw and then bid just below their withdrawn bid to signal a willingness to not compete. To manage eligibility, bidders would bid on items for which they did not have value to maintain activity without showing their hand on what they were interested in bidding for (this was called "parking"). That prompted several auction-rule adjustments. Two notable rule changes implemented were restrictions on jump bidding (the allowable increment when raising your bid) and restrictions on the number of withdrawals allowed (this rule was precipitated by concerns that bidders were using such withdrawals to "game" the auction as opposed to using them to eliminate financial risk).

Based on the previous problems associated with the SMR design and spurred by the FCC-sponsored debate, several new designs have emerged.

\section{Auction Designs for Complex Environments}

It is quite natural for an auction participant to wish to reveal as little as possible concerning his interest and values for particular items or packages in an auction that simultaneously sells multiple items. In general, auction systems that provide feedback and allow bidders to revise their bids seem to produce more efficient outcomes. This feedback feature is the cornerstone of the recent FCC SMR spectrum auctions and many others worldwide. Experience in both the field and laboratory suggests that in complex economic environments iterative auctions, which enhance the ability of the participant to detect keen competition and learn when and how high to bid, produce better results than sealed bid auctions.

An iterative combinatorial auction could allow bidders to explore the bid space without having to place bids for all possible items. Among the iterative designs tried thus far, two specific timing rules have been examined:

1. Continuous auction (see ref. 4): A timer is started and bids can be submitted in real time. The best bid combination that fits within the logistic constraints of the auction is posted. New bids can be tendered at any time and can either be placed on a standby list to be "combined" with others or used immediately to directly replace tentatively winning bids. The standby list is a place where participants can put nonwinning bids to signal to others a willingness to combine to outbid a large-package bid. The auction ends if no allocation-changing bids are submitted during a fixed time period.

2. Multiround (see refs. 6-8): A round begins and sealed bids are submitted. An integer program (IP) is solved to find the highest-valued combination of winning bids. The winners are posted and a new round is started. New sealed bids can be submitted, and the IP is run again to see whether a new solution, with some new winners, is found. When there are no new winners or no new bids, the auction is over.

Another issue in the design of a combinatorial auction involves providing bidders the opportunity to solve the threshold problem. The most obvious approach is to use a sealed bid auction with Vickrey-type pricing, in which it is theoretically in the interest of the participant to reveal his true values. That is, the incentives (your bid does not determine what you pay; that is determined by the bids of others) provided by a Vickrey auction overcomes the threshold problem. In particular, Isaac and James (9) use the standard Vickrey auction, which requires the running of an IP for each winner to determine their price. In ref. 2, the need to run individual IPs for each winner is eliminated and pseudocompetitive prices are used instead by running a specialized linear program to get prices for each item.

Because the iterative and Vickrey sealed-bid approaches are contrary, natural evolution led to an auction design based on combining an iterative process with some form of revelationinducing pricing. This design change was spurred by the fact that in the above-mentioned iterative processes, the value of the information as a basis for determining where and how much to bid in the next round was unknown because participants still had to solve an IP problem based on all previous bids to determine what it would take to combine with others to replace one or more current winning bids. Without prices to guide bidders, the iterative process can become extremely burdensome and, moreover, may make it difficult for bidders to overcome the threshold problem.

In ref. 4, computationally intensive iterative process is implemented where in each round Vickrey prices are computed for each item and delivered to each bidder along with a set of bids that, if submitted in the next round of the auction, would displace the bids submitted by one or more current high bidders, assuming that no other bidders change their bids. Following the pseudocompetitive pricing discussed in ref. 2, Kwasinka et al. (6) use a procedure to calculate prices as feedback information to bidders. They find that provision of this price information allows bidders to identify competitive bids more easily and, in so doing, generate greater auction revenue and a more efficient assignment of items.

Although more efficient, these designs still require solving multiple IP problems each round and, thus, are still subject to computational complexity and scaling-up concerns. To solve this problem, Rothkopf et al. (10) would simply limit the type and number of bids that can be submitted. In ref. 4, the computational burden of the auctioneer is eliminated through decentralization, requiring the bidders to execute any computations to determine on what and how much to bid.

More recently, in response to an FCC request for proposals for a new combinatorial auction design, the authors of ref. 11 proposed and we tested a hybrid auction system that combines multiround and continuous bidding periods. It also implements various activity rules that mimic those in the original SMR auction along with some new variable and more-complicated activity rules.

The systematic results thus far derived from the body of laboratory-controlled studies of the above mechanisms are:

1. There is little evidence that the threshold problem is of great concern.

2. Iterative processes seem to be of assistance to bidders.

3. Price-feedback information provides for bidder transparency. ${ }^{\mathrm{h}}$

hBy transparency, we mean that bidders can easily determine what bid amount would be the current winner of a set of items. 
Table 1. Case 1 values generating join factors and own effects

\begin{tabular}{|c|c|c|c|c|c|c|c|c|c|c|c|c|}
\hline & $A$ & B & C & $\mathrm{D}$ & $E$ & $\mathrm{~F}$ & G & $\mathrm{H}$ & I & $J$ & Value, \$ & Bidder no. \\
\hline Optimal allocation & $\mathrm{X}$ & $x$ & & $x$ & & & & & & & 100 & 1 \\
\hline \multirow[t]{4}{*}{ of 10 licenses } & & & $x$ & & & & & & $x$ & & 80 & 2 \\
\hline & & & & & $x$ & & & $x$ & & & 80 & 3 \\
\hline & & & & & & $x$ & $x$ & & & & 120 & 4 or 6 \\
\hline & & & & & & & & & & $x$ & 50 & 5 \\
\hline $\begin{array}{l}\text { Second-best allocation } \\
\text { of } 10 \text { licenses }\end{array}$ & $\mathrm{X}$ & $x$ & $x$ & $x$ & $x$ & $x$ & $x$ & $\mathrm{X}$ & $x$ & $x$ & 350 or 301 & 6 \\
\hline
\end{tabular}

\section{Computational burden must be taken seriously.}

Relying on these results, its own experience with previous real auctions, and consulting advice, the FCC, for its upcoming $700-\mathrm{MHz}$ auction, has designed a new multiround process that limits the number of package bids that each bidder can submit (12 items and 12 package bids) and the prices at which they can be submitted, provides computationally intensive feedback prices similar to the pricing approach (6) and includes a typical cluster of activity rules. These proposed FCC auction rules for the $700-\mathrm{MHz}$ auction have not been tested in the laboratory.

\section{The Combinatorial Clock (CC) Auction}

During February through October of 1999, while we were testing versions of the FCC's SMR and the Charles River and Associates (CRA) proposal, we had the chance to carefully observe hundreds of auction participants' behavior and the outcomes their strategies generated. Taking seriously the problem of computational burden associated with generating prices in moderately sized combinatorial auctions, yet not willing to impose activity constraints that interfere with bidding transparency by limiting types and numbers of bid revisions, we developed a simple auction design: the CC auction. Our objective was efficiency in achieving all gains from exchange, task simplicity for the bidders, efficacy in handling complexity in the allocation problem, and computational feasibility.

Experiments conducted in 1988 (12) demonstrated that occasionally simple ascending English auctions can become inefficient because of overstated ("jump") bids intended to forestall or signal competition. In the laboratory, we found that the threat of financial exposure aggravates this behavior during an SMR auction for multiple items. The solution in ref. 12 is a simple upward-ticking clock controlled by the auctioneer to remove active-bidder price control. The CC, following this lesson, created a unique price for each item that is controlled by that item's clock (if there is more than one unit of an item available, then the clock price for that item applies identically to all the units available). The price ticks upward only when there is excess demand for an item.

The process we devised is simple and quite transparent. The clocks, one for each item, are started at low prices. Each round's bidders are given a fixed amount of time to submit which packages or individual items they would like to purchase at the current clock prices. A simple algorithm then counts up the demand for each item by each bidder, making sure not to double-count licenses that appear in multiple bids. The item demands then are aggregated across participants. For items that have more than one bidder demanding more units than are available, the clock price is raised. A new round is started, and new bids are requested.

The CC is transparent because no bidder has to submit a price, and the bidder is free to indicate the contents of any packages that he will buy at the given clock prices. His previous bids for packages at previous prices are remembered and eligible for consideration by the auctioneer unless they are purposefully withdrawn.
The auction continues as long as there is excess demand for one of the items being offered. If the auction reaches a point at which there is exactly one bid left for each unit of each item available, then it ends and the standing bidders are awarded the items at the current clock prices: no computation is required!

However, it can happen that, after a particular clock price increases, the demand for that item becomes less than is available. In the case where there is excess supply for at least one item, and demand exactly equals supply for every other item available, then the auctioneer must compute the solution to an IP to find the allocation of items that would maximize his revenue. $\mathrm{He}$ includes all bids at current and previous clock prices that have not been withdrawn. The solution will tend to use old bids to allocate units for which there is excess supply at the current clock prices. If the overall solution does not seek to displace those holding the standing winning bids on items where supply equals demand, the auction is over and bidders pay the prices bid. If the solution does seek to displace at least one bidder holding the standing winning bid on an item where supply equals demand, then that item is considered to have excess demand, the clock price is ticked upward, and the auction continues.

Therefore, the final allocation is one in which all standing bids win items at the final clock prices, and items with excess supply at the final clock prices are awarded at previous clock prices. The auction process that generates this allocation is simply a greedy algorithm to discover pseudo-dual upper-bound prices (see ref. 2 for a thorough description of pseudo-dual price computation): The lowest prices (final clock prices) at which everyone who submitted a bid is definitely declared a winner. In complex environments, these prices are often not unique, and this allows the auction mechanism some flexibility in achieving an efficient outcome. ${ }^{i}$

The beauty of the CC auction is in its simplicity to the participant and its minimal computational requirements of the auctioneer. It trivially accommodates the sale of multiple units of multiple items. Bidders have complete freedom to move in and out of the auction bidding on any packages at will. It allows the bidder to impose logical constraints without increasing the computational burden during the auction. For example, a bidder may submit mutually exclusive bids and "if and only if" bids: The auction simply computes his demand for an item as the maximum number of units he could possibly win. The bidder is also free to blend current and previous clock prices in a current compound bid as long as part of his bid is at current clock prices. ${ }^{j}$ The CC auction is an extremely flexible combinatorial auction that we know of. Strategic behavior is controlled further by feeding back only that information which bidders need to know (item prices) to avoid bidding more than their maximum willingness to pay.

'For example, if a winning bid is for a package containing one unit of item $\mathrm{C}$ and one of item $D$, then the bidder isn't concerned with whether the winning prices are 40 and 60 or 60 and 40 , respectively, as long as they eliminate his competition and have a total cost less than he is willing to pay.

FFor example a bid on a package containing items $C$ and $D$ at current clock prices in round $t$ can be resubmitted as a package in round $t+1$ by bidding on one item at the previous (pre) price as long as at least one item is bid at the current new price: for example, $\{C, D\}_{t}$ can become $\{p r e C, D\}_{t+1}$. 
Table 2. Cases $2 a$ and $2 b$, values generating join factors and own effects

\begin{tabular}{|c|c|c|c|c|c|c|c|c|c|c|c|c|}
\hline & A & B & $\mathrm{C}$ & $\mathrm{D}$ & $\mathrm{E}$ & $\mathrm{F}$ & G & $\mathrm{H}$ & 1 & J & Value, \$ & Bidder no \\
\hline \multirow{8}{*}{$\begin{array}{l}\text { Optimal allocation } \\
\text { of } 10 \text { licenses }\end{array}$} & $x$ & & & & & & & & & & 17.37 & 4 \\
\hline & & $x$ & & & & & & & & & 36.27 & 5 \\
\hline & & & $x$ & $x$ & $x$ & & & & & & 88.59 & 1 \\
\hline & & & & & & $x$ & & & & & 24.00 & 2 \\
\hline & & & & & & & $x$ & & & & 30.00 & 4 \\
\hline & & & & & & & & $x$ & & & 36.00 & 3 \\
\hline & & & & & & & & & $x$ & & 48.00 & 1 \\
\hline & & & & & & & & & & $x$ & 54.00 & 5 or 6 \\
\hline Second-best allocations & & & & & & $x$ & $x$ & $x$ & $x$ & $x$ & 180 or 153 & 5 \\
\hline of 10 licenses & $\mathrm{X}$ & $x$ & $x$ & $x$ & $x$ & & & & & & 114 & 1 \\
\hline
\end{tabular}

For this purpose, bidders do not need to know who is bidding, how many are bidding, and on which items or packages they are bidding.

\section{Auction Tests}

After having conducted a series of experiments that tested versions of the CRA combinatorial auction and the FCC's SMR auction, in the fall of 1999 we continued by independently testing our own invention: the CC auction. All the test auctions offered only one unit of each of 10 items for sale. Ten bidders each had different values for various packages of items. The value distributions that we created used variations on the following conditions to test the efficacy of the auction designs:

Condition 1: The Joint-Value Factor. This measures the relative difference between the value of the optimal allocation $\left(V^{*}\right),{ }^{\mathrm{k}}$ which was constructed to include several smaller bidder packages, and the next-highest value allocation $(\hat{V}),{ }^{1}$ which was constructed to include a single bidder's package covering the optimal set of smaller packages. We define the joint-value factor as the ratio $J=\left(\hat{V} / V^{*}\right)$. The larger the value of $J$, the greater the need for bidders to coordinate their bids to "defeat" the bidder with the highest package bid. This coordination is made difficult by the incentive that bidders have to "free-ride" off the bid increases of other bidders. Note that as $J$ approaches 1 , the relative loss in efficiency from having the big bidder win approaches $0 . J$ directly measures the best possible market efficiency that can result when the auction fails to solve the threshold problem.

Condition 2: The Own Effect. This effect is one that is coupled with the join factor. It occurs when $b$ is the large-package bidder who demands but $b$ is also one of the small-package bidders included in $V^{*}$. To achieve the optimal allocation, $b$ must forego his large package to be included in the optimal allocation of smaller winning packages. Efficiency may be hurt because $b$ may not collaborate in his role as a small-package bidder for two reasons: (i) he may feel he is in a stronger negotiating position (because he owns the large package) and may demand more of the surplus than other small-package bidders; or (ii) he may think that displacing himself, even if it is apparently profitable, may create unpredictable dynamics in the subsequent bidding.

Tables 1 and 2 show optimal and second-best allocations for the various boundary experiments we conducted to sell 10 licenses (A-J) with different values to different bidders. Com-

${ }^{k} V^{*}$ is the value of the maximization problem max $\Sigma v_{j} x_{j}$ subject to $x_{j \varepsilon}\{0,1\}$ and $\Sigma x_{j} \cdot y_{j} \leq Y$, where $v_{j}$ is the value for package $j_{1} y_{j}$ is the vector of elements of package $j$, and $Y$ is the vector of total supply.

I $\hat{V}$ is the value of the $\max \left\{v_{1 Y}, \ldots, v_{n Y}\right\}$, where $v_{i Y}$ is the value of participant $i$ for the entire supply $Y$. plete value parameters for these experiments can be found at http://ices3.gmu.edu/FCC_Parameters.

In case 1 (Table 1), bidder 6 has value for the superpackage and is either included in the optimal allocation or not depending on whether he owns the package ( $\mathrm{F}$ and $\mathrm{G})$. The join is either high, $0.81(350 / 430)$, or low, $0.70(301 / 430)$, depending on bidder 6's assigned value for the superpackage.

In case 2 (Table 2), the licenses were divided into two separable groups of five, $2 \mathrm{a}$ and $2 \mathrm{~b}$, with separate join factors and own effects within each group and with no bidders valuing packages containing licenses in both groups. For licenses A-E, several bidders had values for the entire license group from A to E, and some of them had values for packages that were part of the optimal allocation. In the second group of licenses F-J, each bidder had values for single licenses except bidder 5, who had value for the entire group of licenses F-J. We divided the separable outcomes of the two groups into cases $2 \mathrm{a}$ and $2 \mathrm{~b}$, respectively.

In total, 55 test auctions were executed. Student participants, bidding anonymously through a local area network of computers, earned significant cash payments for their bidding successes. Table 3 shows the allocation efficiencies for all the CRA, SMR, and $\mathrm{CC}$ auctions.

Results. When comparing the outcomes of the noncombinatorial SMR (used until now by the FCC) against the outcomes of the

Table 3. CC auction vs. CRA vs. SMR

\begin{tabular}{|c|c|c|c|c|}
\hline Case & Join & Own & Auction & Allocation efficiency, \% \\
\hline \multirow[t]{3}{*}{1} & 0.81 & Yes & $\mathrm{CC}$ & $100,100,100$ \\
\hline & & & CRA & $78,79,78$ \\
\hline & & & SMR & 59 \\
\hline \multirow[t]{3}{*}{1} & 0.81 & No & $\mathrm{CC}$ & $100,100,100$ \\
\hline & & & CRA & 97,79 \\
\hline & & & SMR & 63 \\
\hline \multirow[t]{3}{*}{1} & 0.70 & Yes & $\mathrm{CC}$ & $100,100,100,100$ \\
\hline & & & CRA & 100,100 \\
\hline & & & SMR & 70 \\
\hline \multirow[t]{3}{*}{$2 a$} & 0.80 & Yes & $\mathrm{CC}$ & $100,100,99,100,99,100$ \\
\hline & & & CRA & $99,99,99,95,94,95,95$ \\
\hline & & & SMR & $100,99,95,95$ \\
\hline \multirow[t]{3}{*}{$2 b$} & 0.94 & Yes & $\mathrm{CC}$ & $100,100,100$ \\
\hline & & & CRA & $91,94,94$ \\
\hline & & & SMR & 100 \\
\hline \multirow[t]{3}{*}{$2 b$} & 0.94 & No & $\mathrm{CC}$ & $100,100,100$ \\
\hline & & & CRA & 95,95 \\
\hline & & & SMR & 100 \\
\hline \multirow[t]{3}{*}{$2 b$} & 0.80 & Yes & $\mathrm{CC}$ & $100,100,100$ \\
\hline & & & CRA & 100,91 \\
\hline & & & SMR & 100 \\
\hline
\end{tabular}


combinatorial auction originally solicited by the FCC from CRA, we find the following results.

Result 1. As the join factor increases, efficiency falls. The own effect also reduces efficiency. Although efficiencies are low for the CRA auction in case 1, they are higher than for the SMR auction. In case $2 b$, in which bidders only have values for single-license packages except for one bidder, who has a value for all the licenses, the SMR auction outperforms the CRA auction. Result 2. The more transparent and simpler $\mathrm{CC}$ auction was uniformly more efficient than both the other auction mecha-

1. Bykowsky, M., Cull, R. \& Ledyard, J. (2000) J. Regul. Econ. 17 (3), 205-228.

2. Rassenti, S., Smith, V. \& Bulfin, R. (1982) Bell J. Econ. 13, 402-417.

3. Porter, D. (1999) Rev. Econ. Des. 4, 73-97.

4. Banks, J., Ledyard, J. \& Porter, D. (1989) Rand J. Econ. 20, 1-25.

5. Ledyard, J., Olson, M., Porter, D., Swanson, J. \& Torma, D. (2002) Interfaces 32 (5), 4-12.

6. Kwasinka, T., Ledyard, J., Porter, D. \& DeMartini, C. (1999) A New and Improved Design for Multi-Objective Iterative Auctions, Caltech Social Science Working Paper No. 1054 (California Institute of Technology, Pasadena).

7. Charles River and Associates Inc. \& Market Design Inc. (1998) Report 1A: Auction Design Enhancements for Noncombinatorial Auctions, Charles River and Associates Report No. 1351-00 (Charles River and Associates, Cambridge, MA). nisms across all the test environments. In addition, it yielded $100 \%$ efficiency in all but two of the test auctions.

\section{Conclusion}

The consistency of the CC test auction outcomes is remarkable given the typically somewhat noisy results of laboratory experiments with human subjects. As simple as it is, the $\mathrm{CC}$ auction is extremely promising and merits continuing study in a variety of other auction environments.

8. Charles River and Associates Inc. \& Market Design Inc. (1998) Report 1B: Package Bidding for Spectrum Licenses, Charles River and Associates Report No. 1351-00 (Charles River and Associates, Cambridge, MA).

9. Isaac, R. \& James, D. (2000) Exp. Econ. 3, 31-53.

10. Rothkopf, M., Peke, A. \& Harstad, R. (1998) Manage. Sci. 44, 1131-1147.

11. Charles River \& Associates Inc. and Market Design Inc. (1998) Report 2. Simultaneous Ascending Auctions with Package Bidding, Charles River and Associates Report No. 1351-00 (Charles River and Associates, Cambridge, MA).

12. McCabe, K., Rassenti, S. \& Smith, V. (1988) Testing Vickrey's and Other Simultaneous Multiple Unit Versions of the English Auction, revised by Isaac, R. M., ed. (1991) Research in Experimental Economics (JAI, Greenwich, CT), Vol. 4. 